\title{
On the Teaching of Electrical Machines and Drive Systems
}

\author{
Essam S Hamdi and John Paul Spivey \\ School of Science, Engineering \& Design \\ Teesside University, Middlesbrough TS1 3BA, UK \\ e.hamdi@tees.ac.uk_p.spivey@tees.ac.uk
}

\begin{abstract}
This paper presents a unified approach concerning the production of torque in electrical machines (excluding the reluctance type) and demonstrates its application to conventional as well as more advanced configurations. Such an approach enables integration of electrical machines teaching with relevant power electronic converters and control schemes. The paper reports on the authors' experience in developing first modules in Electrical Machines and Drive Systems at Teesside University.
\end{abstract}

Index Terms - Electric machines, unified treatment, drive systems, curriculum development, engineering education, power electronics.

\section{INTRODUCTION}

During the last century, Electrical Machines formed the core of Electrical Engineering Programmes. Today, Electrical Machines can only occupy a modest portion of the Programme so that more time may be devoted to covering continuing development in other related fields.

In most textbooks, electrical machines are categorised into three main types: synchronous, induction and DC. The treatment of each type follows the same pattern: its construction and theory of operation are described followed by the development of an equivalent circuit; which is then used to determine its performance under various operating conditions.

Today, a considerable number of different machines have been devised and the whole subject has become so vast that to teach it on this basis is unsatisfactory. Indeed, teaching of electrical machines was modified to incorporate power electronics, during the 1980's and early 1990's, and further modified by the turn of the millennium to include closed-loop control, in today's Electric Drive Systems [1]-[6].

Bespoke variable-speed electric drive systems continue to replace mechanical and hydraulic systems in a wide range of applications. This is not only due to environmental considerations but also as electric drive systems, in most cases, offer higher efficiencies and increased reliability [7].

\section{PROGRAMME OVERVIEW}

In designing drive systems modules, the approach favoured by the authors focuses, initially, on motor operation. First, the basic principle of torque production by interaction of two $\mathrm{mm} f \mathrm{~s}$ is introduced, then different ways of engineering it are described. Such a unified treatment emphasises, from the outset, that synchronous, induction and DC motors and many other topologies, all utilise the same concept and that their individual characteristics are due to the way they are engineered. This facilitates coverage of various special machine topologies that are employed in modern drive systems and provides insight to relevant converter topologies and control objectives.

Learning outcomes (LOs) specify what students will be able to do on completion of the programme. In the UK, universities must be able to satisfy both the Quality Assurance Agency (QAA) and the accrediting body (in the present case, the IET) that LOs are met and this must be considered at the programme design stage. The philosophy of developing learning outcomes for all the Electrical and Electronic Engineering core modules at Teesside University (TU) are that, learning outcome statements are written using Bloom's taxonomy [8], they are mapped into the QAA and the TU's level descriptors and then constructively aligned to the module's assessment. The module outcomes, for all modules, are then mapped against the programme outcomes and relevant level descriptors [9].

The structure of the Electrical and Electronic Engineering programme at TU includes three 20-credit modules dealing with Drive Systems. The first is a level 5 module (the second year of the BEng/MEng programme), delivered in the second semester. This module is delivered over a 12-week semester, 4 hours per week (divided equally between lectures and laboratory sessions) and it contains the following topics:

- Machine fundamentals: a unified treatment of the production of torque and emf,

- Magnetic materials: soft and hard magnetic materials and fundamentals of magnet design,

- DC-DC and AC-DC converters and their application in DC drive systems (open-loop control) and,

- Closed-loop speed and torque control

The second drive systems module is delivered at level 6 and it covers the following topics:

- DC-AC converters,

- Constant V/f induction motor drives,

- Introduction to motor CAD and,

- Permanent-magnet synchronous and brushless DC drives.

The advanced elective module (level 7) focuses on designing and testing high performance, permanent magnet, drive systems using hardware-in-the loop (HIL) simulation techniques. For completeness, the programme 
includes a level 7 module dealing with power electronic converters design and applications (with a focus on power systems applications).

\section{TORQUE PRODUCTION IN ELECTRICAL MACHINES - A UNIFIED APPROACH}

In the first drive systems module, torque production is introduced, from basic principles, as a result of interaction between two $m m f$ s. With reference to the primitive magnetic circuit of Fig. 1-a, the $m m f s$ produced by the stator and rotor excitation $\left(\mathrm{F}_{\mathrm{R}}\right.$ and $\left.\mathrm{F}_{\mathrm{S}}\right)$ are aligned and $\mathrm{N}-\mathrm{S}$ and $\mathrm{S}-\mathrm{N}$ magnetic 'poles' produce opposing radial forces equal in magnitude on opposite sides of the rotor (if it is perfectly centred). If the rotor is rotated an angle $\delta$ (as shown in Fig. 1-b), the quadrature component of the rotor $m m f$ produces a tangential force and torque trying to bring the rotor back to its initial position. Assuming that the magnitude of the $m m f s$ is constant, the torque is at a maximum when $\delta=90^{\circ}$ (electrical).

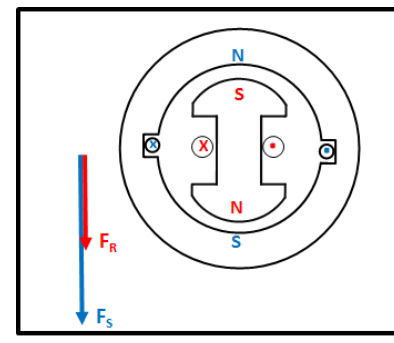

a

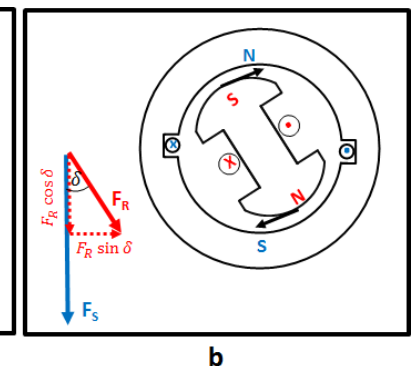

Fig. 1. Production of torque in a primitive electrical machine.

Of course, it is not essential for the torque production that the stator and rotor magnetic axes are stationary in space. However, the angular displacement between the two axes must be preserved. In the following, torque production in conventional machines is discussed, illustrating that different machine types represent a different way of engineering this basic principle.

\section{A. Torque in DC Machines}

Fig. 2 shows a simplified 2-pole DC machine. The conventional dots and crosses notation is used to indicate the current direction of the armature's coil sides. The armature winding is always of the double-layer type; each coil has one side in the top of a slot and the other side in the bottom of the slot situated a pole-pitch away (here, diametrically opposite). A closed winding is formed by connecting the coil sides to a commutator segment.

The connections of the coil sides to the commutator segments together with the end connections for coils in slots 1 and 7 are shown in Fig. 2-a. A current entering the right-hand brush (which, at the instant shown, is in contact with commutator segment 1) divides into two halves. One half of the armature current flows through the inner coil side in slot 1 and ends up at the other brush in contact with segment 7 . The other half flows through the outer coil side in slot 6 and ends up at segment 7. This yields the spatial current distribution depicted in Fig. 2-a; producing an mmf in the vertical direction.

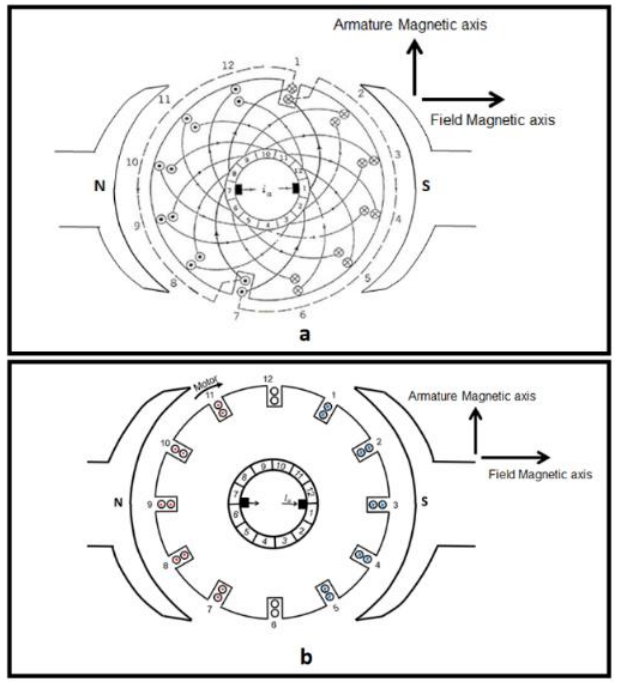

Fig. 2. Production of torque in a conventional DC machine.

The resulting torque will be in the clockwise direction trying to align the armature and field $m m f$ s. Fig. 2-b shows the spatial current distribution after the motor has rotated an angle equivalent to half a commutator segment. This leads to coil sides in slots 12 and 6 being short-circuited by the brushes. Currents in other armature coil sides still produce a magnetic field in the vertical direction. After further rotation, the brushes will be in contact with segments 12 and 6 and slots 12 and 6 will occupy the positions previously occupied by slots 1 and 7 in Fig. 2-a.

The action of the commutator is, therefore, much more significant than being just a mechanical rectifier (as some textbooks and educators imply). It yields a current distribution pattern that is fixed in space; resulting in the armature $m m f$ being, always, perpendicular to the excitation (field) $m m f$ (i.e. $\delta=90^{\circ}$ ).

Introducing torque production in this way prepares students for studying machine topologies in which "commutation" is achieved with the aid of power electronic switches (as in Brushless DC Motors). For example, the field windings and poles are replaced with permanent magnets as shown in Fig. 3a. The configuration is then reversed by placing the magnet excitation system on the rotor and the armature winding (now fed from a power electronic converter) is placed on the stator, as shown in Fig. 3-b. The power electronic converter feeding the armature (stator) winding must perform the function of the commutator; producing an $m m f$ that is leading the rotor $m m f$ by an angle $\delta$.

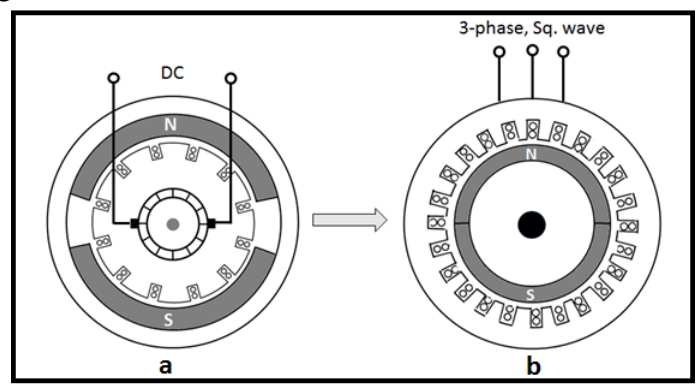

Fig. 3. Development of the Brushless DC Motor. 
The principle of operation of the power electronic converter is introduced at this stage. Fig. 4 introduces students to the concept of producing a rotating $\mathrm{mmf}$ by means of power electronic switching. It shows a simplified stator winding, a typical converter arrangement, a common switching strategy and the resulting phase currents. In order to emulate the function of the commutator of a conventional machine, the stator $m m f$ has to lead the rotor $m m f$ by an angle $\delta$ and, of course, rotate at the same speed in order to preserve the displacement. This can be achieved by introducing rotor position sensors and utilise them to determine the required switching pattern of the power electronic converter.

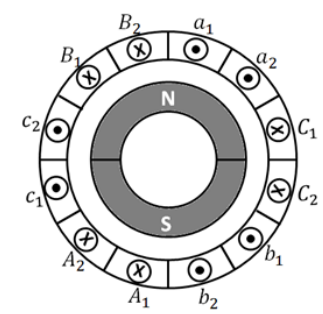

a

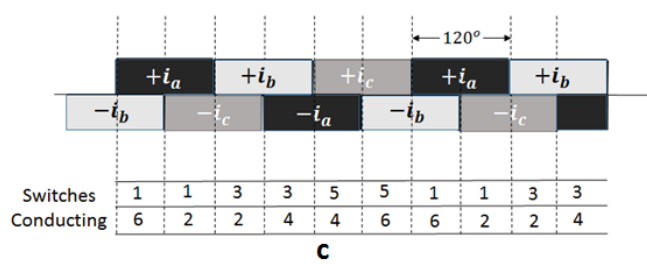

Fig. 4. Operation principle of a brushless DC motor: (a) a stator winding arrangement, (b) a typical converter configuration and (c) switching and current patterns.

\section{B. Torque in Induction Motors}

The stator of an induction motor is provided with a threephase symmetrical winding which, when connected to a threephase balanced supply, produces a rotating magnetic field in the air-gap. At starting, the relative speed between the rotating field and the stationary rotor is the synchronous speed, $n_{s}$. Therefore, an emf is induced in the rotor at the supply frequency. Consequently, a current $\left(I_{r}\right)$ is established, producing a magnetic field that is rotating (with respect to the stationary rotor) at a speed $n_{s}$. Coupling between stator and rotor magnetic poles is established resulting in a tangential force and the rotor starts to rotate at a speed $n_{r}$. The frequency of the rotor emf and current is proportional to $\left(n_{s}-n_{r}\right)$ and the speed of rotation of the rotor magnetic field (with respect to the rotor) is $\left(n_{s}-n_{r}\right)$. At any rotor speed, the speed of the magnetic field produced by the rotor current, with respect to a stationary reference frame, is $n_{s}$; as is illustrated in Fig. 5.

Torque production in an induction motor can also be explained with the aid of the concept of the circle diagram [10]. Assuming the mutual flux and rotor flux linkage to vary as $\sin \omega t$, the induced rotor emf (E) will be a cosine function. The rotor current is then expressed as:

$$
I_{r}=\frac{E}{\left({ }^{r_{r} / s}\right)+j x_{r 2}}
$$

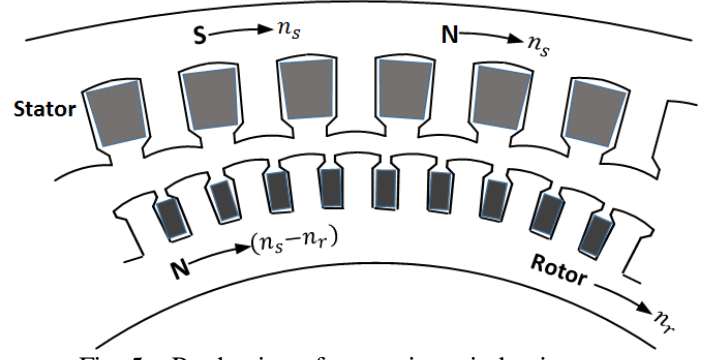

Fig. 5. Production of torque in an induction motor.

Fig. 6 shows the locus of the rotor current and the torqueslip characteristics for an induction motor, as the slip changes from 1 to 0.04 . As the slip decreases, the impedance of the rotor circuit increases and becomes more resistive. As a result, the rotor circuit power factor angle (between $E$ and $I_{r}$ ) and the magnitude of the rotor current both decrease. The rotor $m m f$ is proportional to the rotor current. Therefore, as the slip decreases the load angle (between $\phi_{m}$ and $\phi_{r}$ ) increases but the magnitude of the rotor flux, $\phi_{r}$, decreases. Thus, the torque is maximum when the product $\phi_{m} \phi_{r} \sin \delta$ is maximum.

At starting, the rotor power factor angle is determined as $\tan ^{-1}\left[\frac{x_{r}}{r_{r}}\right]$. Therefore, there will always be an angle between rotor and stator mmfs and induction motors exhibit starting capability; as is illustrated in Fig. 6. It may be noted that such an approach underlines the fact that starting currents of induction motors are significantly higher than the full-load values.
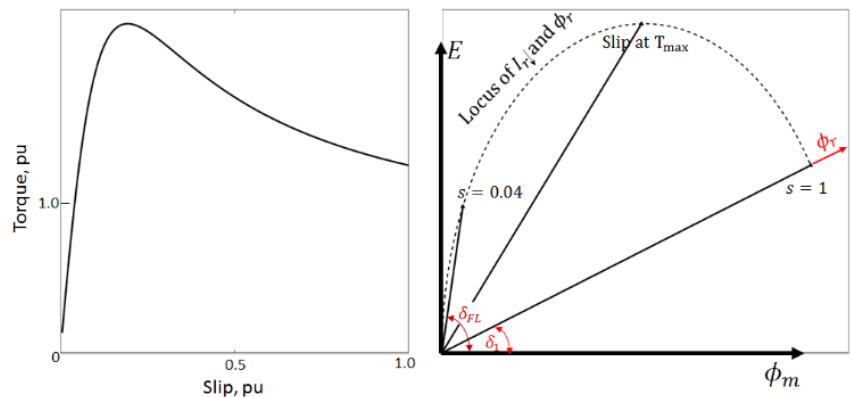

Fig. 6. Locus of rotor current and flux (right) and the resulting torque-speed Characteristics (left).

\section{Torque in Synchronous Machines}

As torque is introduced as a result of interaction between two $m m f s$ (or poles on the opposite side of the air-gap), it follows that, in a synchronous machine, the rotor must be provided with a field system having the same number of poles as the stator winding.

At starting, the stator magnetic field (poles) rotate at the synchronous speed and no angle can be established with the stationary rotor poles. Therefore, synchronous machines do not exhibit self-starting capabilities. However, if the rotor is brought up to the synchronous speed (by an external primemover or other added design features), there will be no relative motion between the magnetic axes and a unidirectional force will be developed. Unlike the DC machine, the angular 
displacement between the $m m f s$ axes is not constant but varies with the load, as illustrated in Fig. 7.

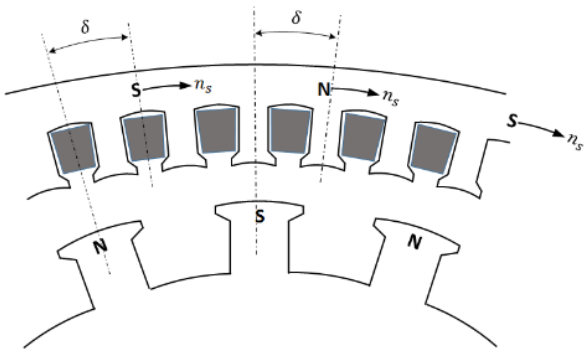

Fig. 7. Production of torque in a synchronous machine.

The conventional synchronous machine used in power generation is not covered in the Drives module. Instead, the treatment focuses on the permanent magnet version that is widely used in industrial and consumer applications. The construction of a permanent magnet (PM) synchronous motor exhibiting a line-start capability is illustrated in Fig. 8 [11]. Such a motor can operate directly on-line or as a component of a drive system incorporating a power electronic converter (similar to that of Fig. 4-b) and a PI controller.

It should be noted that the design of Fig. 8-b is just an illustration. While numerous configurations appear in literature, they are all a derivative of the conventional synchronous machines and operate on the same principle of interaction between two $m m f$ s. Rotors of machines designed for operation with power electronic converters, normally, are not provided with cage windings and the magnets can either be surface mounted or buried in radial rotor slots. These design topologies are further explored with the aid of finite-element (FE) design package.

\section{ELECTROMAGNETIC DESIGN}

The aim of this part of the module is to introduce students to an electromagnetic design software similar to that used in industrial motor design [12]. This is neither intended to delve deep into motor design nor to cover the finite element (FE) method in depth. The treatment starts by introducing the basics of the FE method; it relies on dividing the region to be investigated into smaller ones (pre-processing), solve the electromagnetic field problem (solver) and provide field plots, emf, torque etc. (post-processing).

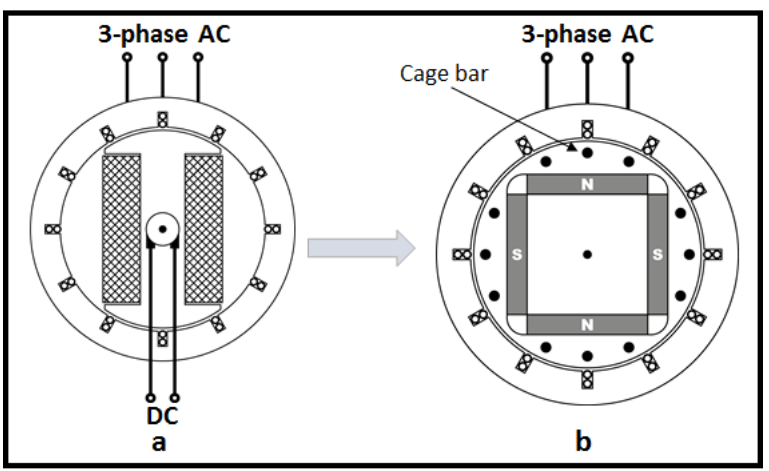

Fig. 8. A conventional synchronous machine (a) and a PM motor.
Students are provided with two designs one utilising surfacemounted magnets and the other interior-magnets, and asked to investigate the air-gap flux density values. An example of the students' work is shown in Fig. 9.
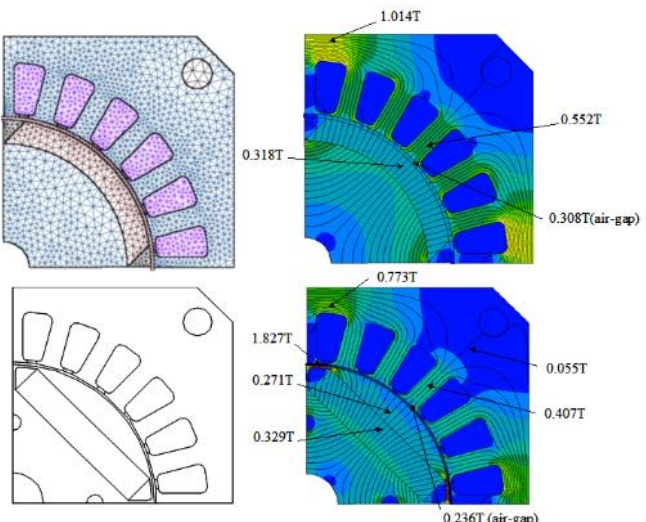

Fig. 9. Magnetic field plots in a surface-mounted magnet (top) and an interior-magnet motor.

\section{EXPERIMENTAL FACILITIES}

\section{A. An Overview of the Laboratory Facilities}

In order to allow students to experiment and learn without endangering themselves or causing serious equipment damage, educational laboratories must be designed with safety in mind. While the equipment need to be compact, results produced must resemble those obtained in real life. One drawback of some educational drive systems laboratories is that they utilise low power motors; typically $300 \mathrm{~W}$. The performance characteristics of such motors are significantly different from those employed in various industrial applications. In particular, the damping factor of such a low power motor is too high and this yields unrealistic dynamic performance, and mistakes in motor control design would not have an obvious effect on performance [6]. Therefore, at Teesside University (TU), $1 \mathrm{~kW}$ motors specifically designed to emulate the parameters of industrial machines, are used.

With reference to Fig. 10, at TU, each drive systems workstation comprises a servo drive (capable of applying user defined load profile to the motor undergoing test), a digital control unit and an interface software (ActiveServo software [13]). The software is installed on and ran via the adjacent networked PC which communicates with the hardware via a USB interface.

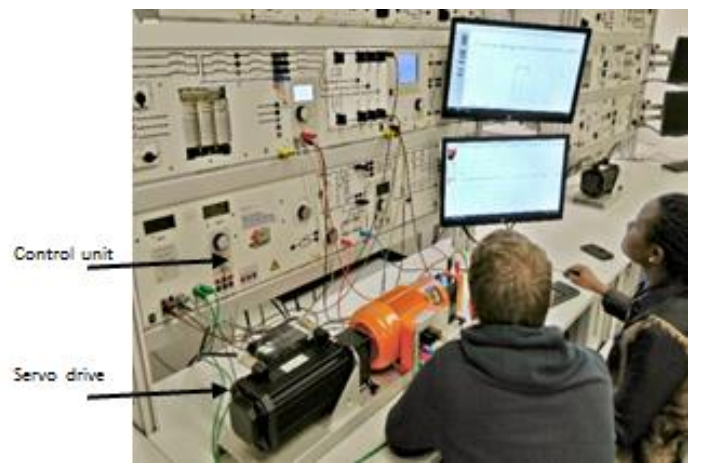

Fig. 10. The drive systems laboratory at Teesside University. 
The servo drive control unit is capable of four-quadrant operation and therefore able to act as a brake or prime mover for the test machine. The unit also monitors the machine under test and unloads it if the temperature exceeds the design value. The servo drive is provided with a speed and position resolver to allow not only control but measurement feedback to the software on the PC. The ActiveServo software enables students to apply load profiles to the test machine. Further software called Labsoft [13] allows students to measure and record values via virtual instruments which are then available at the PC for display and further processing. Graphical user interfaces (GUIs) also allow various control strategies to be easily implemented and optimised.

\section{B. Power Electronic Converters}

Each workstation is provided with two converters, one employing IGBTs (Fig. 11) and the other thyristors (Fig. 12). Fig. 11. shows the main features of the self-commutated converter [13]. The IGBT bridge allows students to investigate the operation of both DC-DC and DC-AC converters. The converters are connected to the PC via the USB port. Selection of converter topologies as well as control functions and output display is performed on the PC using the relevant virtual instrument [13]; as illustrated in Fig 13.

The self-commutated converter allows students to investigate performance of various topologies of choppers and inverters when supplying an R-L load. Then, operation in speed control of both DC and induction motors is investigated. In the advanced drives module, students perform control design using Matlab $^{\circledR}$ and, via the interface (13) of Fig. 11, unique drive systems control strategies are imported and evaluated.

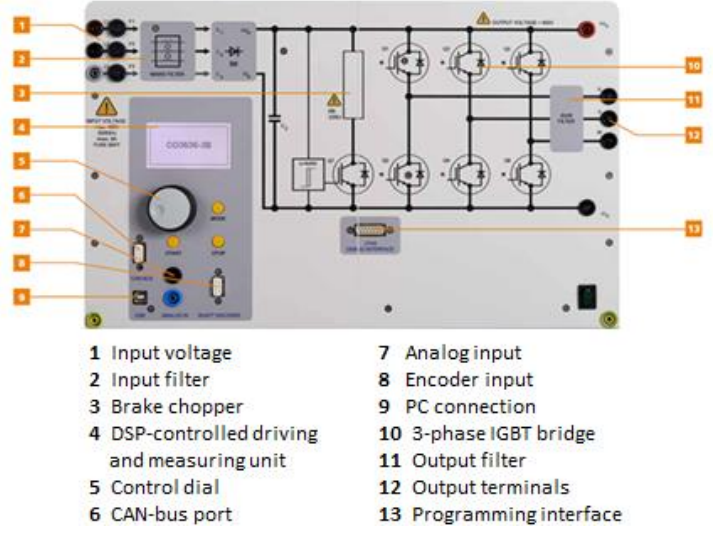

Fig. 11. The self-commutated converter [13].

The line-commutated converter shown in Fig. 12 enables students to investigate operation of controlled and uncontrolled, single-phase and three-phase, half-wave and fullwave rectifiers. The converter is connected to the $\mathrm{PC}$ via the USB port and circuit topology and control is performed with the aid of the relevant instrument panel. Also, the converter enables investigation of $\mathrm{AC}-\mathrm{AC}$ conversion but this does not form a part of TU's drive systems modules.

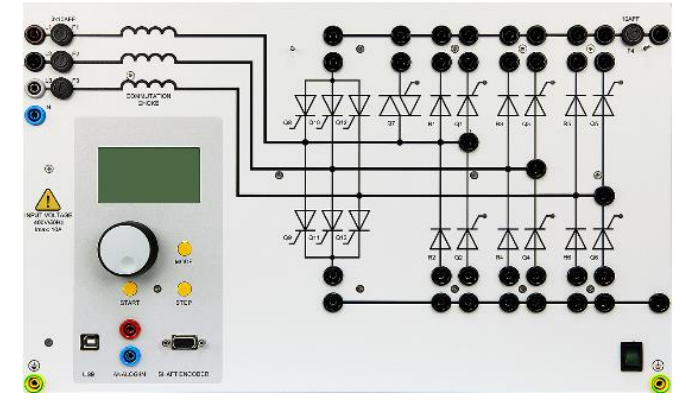

Fig. 12. The line-commutated converter [13].

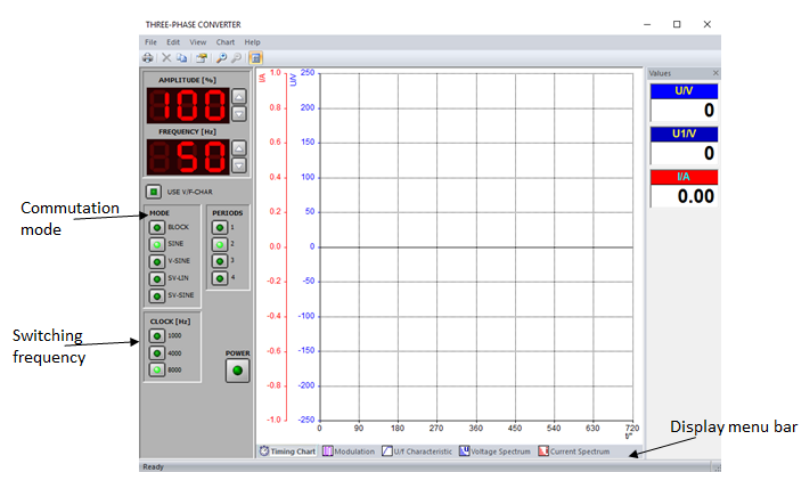

Fig. 13. The self-commutated converter virtual instrument panel [13].

\section{Controller Design}

Basic control engineering knowledge is assumed and students are expected to have covered open-loop control of drive systems in detail prior to embarking on practical activities concerning controller design to meet defined specifications.

Students would have covered determination of drive systems transfer functions (TF) with the aid of the laws of physics, circuit analysis relationships and the relevant torque and emf equations. During the control laboratory sessions, the drive system TF is determined experimentally following a modified reaction curve method. Then, Controller parameters are determined using established empirical formulae and the effect of each component on response is investigated with the aid of the cascade controller virtual instrument [13]. This is illustrated in Fig 14 where a DC drive system response to a set point change is shown. This one instrument allows students to quickly test differing values and readily witness the system's response.

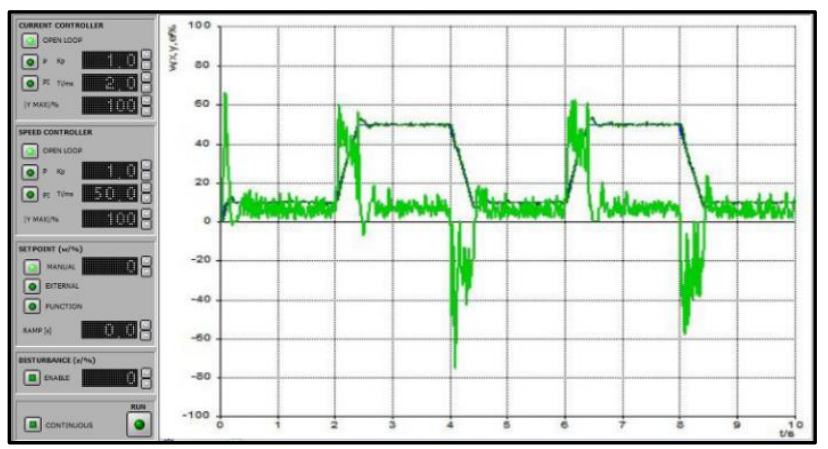

Fig. 14. GUI of the cascade virtual experiment 
At a more advance level the Matlab® plug-in is utilised to develop more complex control architectures; as is illustrated in Fig. 15. The design process then becomes one more familiar to industry, initial development in simulation before moving on to processor and hardware in the loop tests. The results of this process are presented in Fig. 16.

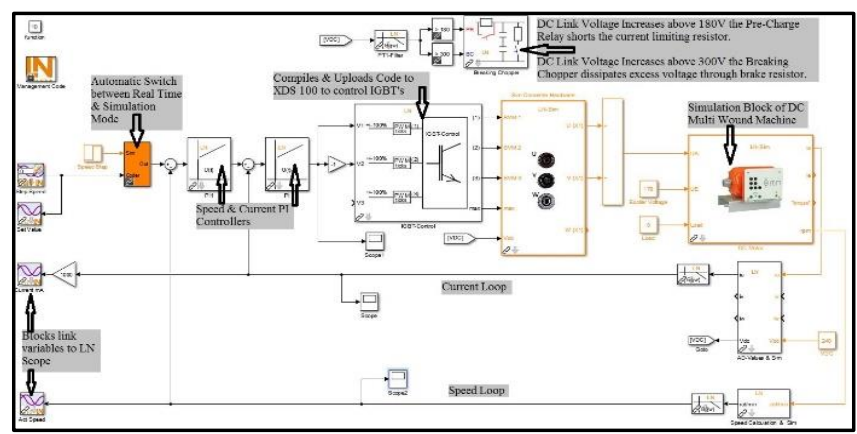

Fig. 15. Controller design utilising HIL Matlab® interface.

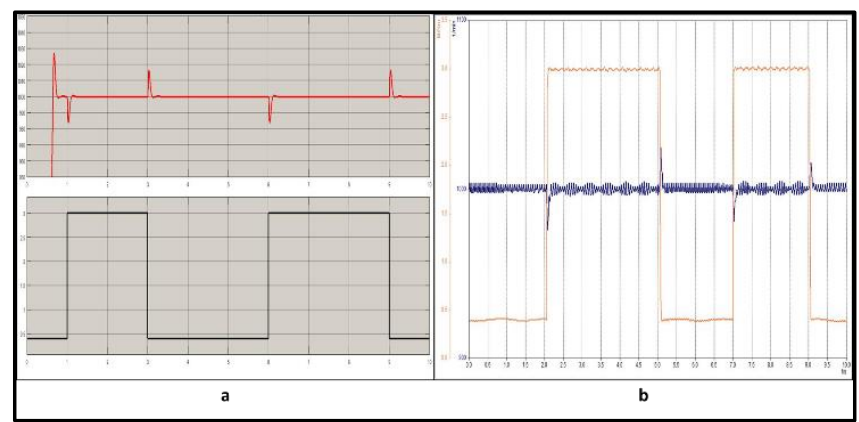

Fig. 16. Simulation (a) and experimental (b) motor speed response.

\section{CONCLUSIONS}

The paper discusses development in electrical machines teaching and argues that this subject is now more related to power electronics and control engineering. Of course, alternators, high-voltage synchronous motors and transformers are still very important topic. However, the authors' believe that, today, they should be integrated within the Electric Power Systems curricula.

A unified treatment of the production of torque in electric machines is presented. Such an approach enables teaching various machine topologies efficiently and facilitates their introduction into closed-loop drive systems. This treatment has been tested on a digital platform [14] and was received favourably by $97 \%$ of some 34000 views.
Due to the increased industrial interest in special machine topologies for electric and hybrid-electric vehicles and wind generation applications, students at TU are introduced to the subject of CAD of electric machines and some students expand their experience of the subject during their graduation projects. This has been shown to enhance their employability.

The electric drive systems laboratory facility at TU is described. It enables students to carry out practical investigations on a variety of systems.

\section{REFERENCES}

[1] P. T. Krein and P. W. Sauer, "An integrated laboratory for electric machines, power systems, and power electronics," IEEE Trans. Power Syst., vol. 7, no. 3, pp. 1060-1066, Aug. 1992.

[2] N. Mohan, W. P. Robbins, P. Imbertson, T. M. Undeland, R. C. Panaitescu, A. K. Jain, P. Jose, and T. Begalke, "Restructuring of first courses in power electronics and drives that integrates digital control," IEEE Trans. on Power Electronics, vol. 18, no. 1, pp. 429-437, Jan. 2003.

[3] V. Giri, "A pedagogically effective structured introduction to electrical energy systems with coupled laboratory experiences," IEEE Trans. Power Syst., vol. 19, no. 1, pp. 129-138, Feb. 2004.

[4] R. S. Balog, Z. Sorchini, J. W. Kimball, P. L. Chapman, and P. T. Krein, " Modern laboratory-based education for power electronics and electric machines," IEEE Trans. on Power Systems, vol. 20, no. 2, pp. 538-547, May 2005.

[5] M. Dal, "Teaching electric drives control course: Incorporation of active learning into the classroom', IEEE Trans. Educ., vol. 56, no. 4, pp. 459469, Nov. 2013.

[6] A. Anuchin, and Y. Vagapov, "Instructional laboratory for practical investigation of electric drive control," IET Circuits, Devices \& Systems, vol. 11, issue 4, pp. 344-351, 2017.

[7] A. M. El-Refaie, "Growing role of electrical machines and drives in electrification," in Proc. XXII International Conf. on Electrical Machines( ICEM 2016), Lausanne, Switzerland, 4-7 September 2016.

[8] G. O'Neill, "Curriculum Design in Higher Education: Theory to Practice", UCD, Dublin, 2016.

[9] G. Pillai, N. Winter and E.S. Hamdi, "Development of a master programme in electrical power and energy systems at Teesside university," in Proc. $51^{\text {st }}$ International Universities' Power Engineering Conf.( UPEC 2016), Coimbra, Portugal, 6-9 September 2016.

[10] A. Hughes, Electric Motors and Drives: Fundamentals, Types and Applications, 3rd Edn. Oxford: Elsevier Ltd., 2006.

[11] E. S. Hamdi, Design of Small Electrical Machines, John Wiley \& Sons, 1994 \& 1998.

[12] Motor-CAD Software by Motor Design - EMag, Therm and Lab, Motor Design [Online]. Available: https://www.motor-design.com/motor-cadsoftware/. [Accessed: 23- May- 2018].

[13] Lucas Nülle - Lucas-Nuelle Training Systems for vocational training and didactic, Lucas-nuelle.com [Online]. Available: https://www.lucasnuelle.com/. [Accessed: 23- May- 2018].

[14] E. S. Hamdi, Electrical Machine Fundamentals [online]. Available: https://www.youtube.com/edit?o=U\&video_id=fbwZkhaF0dk. [Accessed: 23- May- 2018]. 